\title{
Qualitative results on the convergence of the $q$-Bernstein polynomials
}

\section{SOFIYA OSTROVSKA and MEHMET TURAN}

\begin{abstract}
.
Despite many common features, the convergence properties of the Bernstein and the $q$-Bernstein polynomials are not alike. What is more, the cases $0<q<1$ and $q>1$ are not similar to each other in terms of convergence. In this work, new results demonstrating the striking differences which may occur in those convergence properties are presented.
\end{abstract}

\section{REFERENCES}

[1] Agratini, O., On certain q-analogues of the Bernstein operators, Carpathian J. Math., 24 (2009), No. 3, 281-286

[2] Andrews, G. E., Askey, R. and Roy, R., Special Functions, Encyclopedia of Mathematics and Its Applications, The University Press, Cambridge, 1999, $664 \mathrm{pp}$

[3] Bernstein, S., Leçons sur les propriétés extrémales et la meilleure approximation des fonctions analytiques d'une variable rêelle, Gauthier-Villars, Paris, 1926

[4] Cooper, S. and Waldron, S. The eigenstructure of the Bernstein operator, J. Approx. Theory, 105 (2000) 133-165

[5] Kaşkaloğlu, K. and Ostrovska, S., On the q-Bernstein polynomials of piecewise linear functions in the case $q>1$, Mathematical and Computer Modelling, 57 (2013), 2419-2431

[6] Landau, L. D. and Lifshits, E. M. Quantum Mechanics, Pergamon Press, 1965

[7] Mahmudov, N., The moments for q-Bernstein operators in the case $0<q<1$, Numer. Algor., 53 (2010), 439-450

[8] Novikov, I. Ya., Asymptotics of the roots of Bernstein polynomials used in the construction of modified Daubechies wavelets, Math. Notes, 71 (2002), 217-229

[9] Ostrovska, S. and Özban, A. Y., On the sets of convergence for sequences of $q$-Bernstein polynomials with $q>1$, Abstract and Applied Analysis, Volume 2012 (2012), Article ID 185948, 19 pages doi:10.1155/2012/185948

[10] Ostrovska, S., A Survey of Results on the Limit q-Bernstein Operator, Journal of Applied Mathematics, Volume 2013 (2013), Article ID 159720, 7 pages

[11] Ostrosvka, S. and Turan, M., On the eigenvectors of the q-Bernstein operators, Math. Methods in the Applied Sciences, in press. doi: $10.1002 / \mathrm{mma} .2814$

[12] Phillips, G. M., Bernstein polynomials based on the q-integers, Ann. Numer. Math., 4 (1997), 511-518

[13] Phillips, G. M., A survey of results on the q-Bernstein polynomials, IMA J. Num. Anal., 30 (2010), 277-288

[14] Videnskii, V. S., On some classes of q-parametric positive operators, Oper. Theory Adv. Appl., 158 (2005), 213-222

[15] Wang, H., Korovkin-type theorem and application, J. Approx. Theory, 132 (2005), No. 2, 258-264

[16] $\mathrm{Wu}, \mathrm{Z} .$, The saturation of convergence on the interval $[0,1]$ for the $q$-Bernstein polynomials in the case $q>1, \mathrm{~J}$. Math. Anal. Appl., 357 (2009), 137-141

DEPARTMENT OF MATHEMATICS

ATILIM UNIVERSITY

INCEK, 06836 ANKARA, TURKEY

E-mail address: ostrovskeatilim.edu.tr

E-mail address: mturaneatilim.edu.tr

Received: 02.09.2013; In revised form: 19.01.2014; Accepted: 23.04.2014

2010 Mathematics Subject Classification. 40A30, 41A10.

Key words and phrases. $q$-integers, $q$-binomial coefficients, $q$-Bernstein polynomials, limit $q$-Bernstein operator, uniform convergence.

Corresponding author: Mehmet Turan; mturan@atilim.edu.tr 